\title{
A CONVENÇÃO DAS NAÇÕES UNIDAS PARA O DIREITO DO MAR: UMA ANÁLISE DAS REGRAS DE CONTRATAÇÃO DE TRIPULANTES BRASILEIROS EM NAVIOS DE CRUZEIRO EM OPERAÇÃO NO BRASIL
}

\section{ARTIGO ORIGINAL}

SANTOS, Daniela Gonçalves Dos ${ }^{1}$

JUNIOR, Adival José Reinert ${ }^{2}$

SANTOS, Daniela Gonçalves Dos. JUNIOR, Adival José Reinert. A convenção das Nações Unidas para o direito do mar: Uma análise das regras de contratação de tripulantes brasileiros em navios de cruzeiro em operação no Brasil. Revista Científica Multidisciplinar Núcleo do Conhecimento. Ano 05, Ed. 03, Vol. 03, pp. 168182. Março de 2020. ISSN: 2448-0959, Link de acesso: https://www.nucleodoconhecimento.com.br/lei/convencao-das-nacoesunidas

\section{RESUMO}

O contrato de trabalho do trabalhador marítimo contratado em solo nacional para laborar, ainda que parcialmente, em águas jurisdicionais brasileiras, a bordo de navio estrangeiro de cruzeiro marítimo, exige especial atenção do Poder Judiciário quando do exame de demanda trabalhista que bate à sua porta. Sabe-se que as relações

1 Pós-Graduada em Direito Internacional pela UNIBF - União Brasileira De Faculdades; Pós-Graduada em Direito Trabalho pela Faculdade Legale; PósGraduada em Direito Empresarial pela EPD - Escola Paulista de Direito; Graduada em Direito pela Universidade São Judas Tadeu.

2 Especialização em Teoria Psicanalítica. Especialização em Orientação,Supervisão e Gestão Escolar Democrática. Especialização em Docência do Ensino Fundamental, Médio e Superior. Graduação em Matemática. 
jurídicas estabelecidas em um navio são regidas, em regra, pela Lei do Pavilhão. Por ela, são aplicáveis ao contrato de trabalho do trabalhador marítimo as leis do país em que o navio tenha obtido registro, como se este fosse sua extensão territorial. Contudo, nem sempre esse registro se dá no país de domicílio daquele que explora o navio como atividade econômica - figura denominada armador, como seria o natural. Aliás, pode-se dizer que, atualmente, há expressiva quantidade de embarcações que são registradas em países que não possuem nenhum vínculo substancial com seus armadores. Essa prática é denominada de bandeira de conveniência. Esses países favorecem o registro da embarcação, concedem benefícios fiscais e possuem legislação trabalhista precária, o que é utilizado pelos armadores como uma estratégia empresarial para obtenção de maiores lucros, e o que, por sua vez, favorece a concorrência desleal entre as companhias marítimas que exploram o setor do turismo náutico, tendendo à precarização do trabalho a bordo das embarcações que adotam tal prática. O objetivo deste trabalho consiste, pois, em analisar as regras de contratação de tripulantes brasileiros em navios de cruzeiro marítimo de bandeira estrangeira em operação no Brasil, bem como os impactos da adoção de bandeira de conveniência nas relações trabalhistas a bordo, dando-se ênfase à questão do conflito de leis trabalhistas no espaço. A adoção de bandeira de conveniência impõe uma análise cuidadosa no que diz respeito à legislação material aplicável ao contrato de trabalho do marítimo.

Palavras-chave: Trabalhador Marítimo, Lei do Pavilhão, Conflito de Leis Trabalhistas no Espaço, Bandeira de Conveniência, Princípio do Centro de Gravidade.

\section{INTRODUÇÃO}

Com efeito, o advento da globalização impactou fortemente todas as relações de trabalho no mundo. Inclusive, fez se desenvolver a indústria de cruzeiros marítimos e alterou, de certa forma, o trabalho marítimo que anteriormente era desenvolvido em suas formas mais tradicionais.

Dessa forma, o trabalho marítimo passou a abarcar inúmeras novas atividades dentro do segmento do turismo náutico. Assim sendo, os armadores de cruzeiros marítimos 
têm contratado, por exemplo, dançarinos, músicos, garçons, comediantes, fotógrafos e massagistas para atividades de entretenimento a bordo.

A origem do trabalho marítimo remonta às origens da civilização, vez que a navegação foi o instrumento empregado pelos povos antigos no intuito de descobrir novas terras para serem exploradas. Entretanto, a maior parte das normas relacionadas ao próprio comércio marítimo eram fruto de usos e costumes, vindo a compor legislações escritas somente num período posterior. A mais antiga legislação codificada contendo disposições sobre o contrato de trabalho do marítimo é o Código de Hamurabi, que, em seu artigo 239, por exemplo, assim dispõe: "Se alguém ajustar um navegante, deverá pagar-Ihe seis gur de cereais por ano" (OLIVEIRA, 1981, p. 49-50).

A regra geral é que os contratos de trabalho dos tripulantes marítimos sejam regidos sob a égide da Lei do Pavilhão da embarcação. Contudo, em virtude da proliferação das bandeiras de conveniência, tal regra merece ser flexibilizada quando verificado que a causa trabalhista possui maior afinidade com outro Direito.

É neste contexto que se apresenta o tema deste estudo, qual seja verificar a possibilidade de incidência da legislação trabalhista pátria em contratos de trabalho de tripulantes de nacionalidade brasileira embarcados em navios de cruzeiro marítimo registrados sob bandeira de conveniência, quando for esse o direito de maior ligação com o tripulante.

A presente pesquisa acadêmica se presta à análise do conflito espacial de normas trabalhistas a partir do estudo das regras de contratação de tripulantes brasileiros em navios estrangeiros de cruzeiro marítimo em operação nas águas jurisdicionais brasileiras, tendo como objeto duas situações: a primeira delas se refere ao trabalhador contratado para laborar somente no Brasil, enquanto a segunda diz respeito ao tripulante contratado para desempenhar atividades a bordo de navio que perpassa tanto por águas territoriais brasileiras quanto por águas internacionais.

Para que fosse possível essa análise, a pesquisa acadêmica partiu da seguinte problemática: é possível que o contrato de trabalho do tripulante brasileiro, contratado 
em solo nacional para laborar a bordo de navio estrangeiro de cruzeiro marítimo, seja regido à luz da Consolidação das Leis do Trabalho?

Com o objetivo de responder essa indagação ao final do trabalho, foi feito um levantamento bibliográfico e jurisprudencial que pudesse dar suporte ao desenvolvimento do tema em questão. Ressalta-se que esse levantamento bibliográfico priorizou os artigos elaborados pela doutrina especializada no assunto, haja vista que os Manuais de Direito do Trabalho tratam o tema com extrema superficialidade. Portanto, o método de procedimento utilizado foi a pesquisa bibliográfica.

\section{INTERNACIONALIZAÇÃO DO TRABALHO MARÍTIMO}

\subsection{PROTEÇÃO DO MERCADO DE TRABALHO DE TRIPULANTES MARÍTIMOS BRASILEIROS EM EMBARCAÇÕES DE TURISMO ESTRANGEIRAS}

O Brasil apresenta um dos maiores potenciais de desenvolvimento do Turismo Náutico do mundo, isso porque possui cerca de $8.500 \mathrm{~km}$ de linha de costa, $35 \mathrm{mil} \mathrm{km}$ de vias internas navegáveis, $9.260 \mathrm{~km}$ de margens de reservatórios de água doce, lagos e lagoas. Além disso, o país é banhado por correntes oceânicas favoráveis à navegação e conta com um clima propício ao esporte e ao lazer náutico, apresentando uma infinidade de paraísos naturais (BRASIL, 2010).

Até o ano de 1995, no Brasil, a navegação de cabotagem - sendo esta compreendida como aquela que se dá entre portos brasileiros utilizando-se exclusivamente a via marítima ou a via marítima e as vias interiores, era proibida para navios estrangeiros. Somente com a Emenda Constitucional n. 7 de 1995 é que se permitiu que embarcações de bandeiras estrangeiras também explorassem o litoral brasileiro. Embora fossem proibidos de praticar a cabotagem, navios vindos do exterior já faziam escala aqui desde 1960 (RAMÔA; FLORES, 2015). 
É nesse contexto que se abrem as primeiras portas para o desenvolvimento do turismo marítimo em nosso litoral.

O surgimento dos cruzeiros marítimos no Brasil aconteceu dentro do processo de um movimento migratório, quando os navios eram empregados como meio de transporte para as pessoas que migravam para os países da América do Sul. A partir dos anos 60 ocorre uma "quebra de paradigma" e o navio, até então fundamentalmente utilizado como condução, passa a ampliar seus serviços, oferecendo, inclusive, atividades de entretenimento a bordo (AMARAL, 2009).

Segundo um estudo feito pela Fundação Getúlio Vargas (FGV PROJETOS, 2015), contratada pela CLIA ABREMAR BRASIL para diagnosticar os impactos econômicos dos cruzeiros marítimos no Brasil durante a temporada 2014/2015 e avaliar a evolução dos dados obtidos em relação a temporada anterior, quatro armadoras atuaram no país neste período analisado: Costa Cruzeiros, Royal Caribbean International, MSC Cruzeiros e Pullmantur.

De acordo com o mencionado estudo, estima-se que o setor de cruzeiros tenha gerado, durante a temporada 2014/2015, aproximadamente, 32.722 postos de trabalho na economia brasileira - resultado $10 \%$ inferior ao computado na temporada 2013/2014, sendo que, do total de empregos gerados, 2.481 foram para a categoria de tripulantes de navios e outros 30.241 foram gerados direta ou indiretamente pelos gastos dos turistas nas cidades portuárias e na cadeia produtiva de apoio ao setor (FGV PROJETOS, 2015).

Entre as temporadas 2004/2005 e 2010/2011, houve um considerável aumento da quantidade de navios e de cruzeiristas no país, mas, desde então, os dados estatísticos têm decaído (FGV PROJETOS, 2015).

Apesar disso, na temporada 2014/2015, que foi encerrada no mês de maio de 2015, 549.619 cruzeiristas $(7,9 \%$ a menos que na temporada anterior) viajaram em 10 navios pela costa brasileira, o que gerou uma receita de $R \$ 747,1$ milhões (resultado 
que significou uma redução de $14,6 \%$ em relação a temporada anterior) (FGV PROJETOS, 2015).

Diante de tais dados, conclui-se que, embora o turismo marítimo seja importante para a movimentação da economia brasileira e um dos segmentos responsáveis por proporcionar considerável parcela de empregos no país, este setor turístico vem perdendo força nos últimos tempos.

As companhias de cruzeiros marítimos alegam inúmeros motivos que têm inibido o crescimento do ramo no país. Dentre esses, a falta de infraestrutura dos portos brasileiros é recorrentemente trazida à tona.

Nesse sentido é a posição de Ramôa e Flores (2014, p. 316):

Um fator inibidor ao crescimento [da indústria de cruzeiros marítimos no Brasil] é relativo à infraestrutura portuária brasileira, que se mostra bastante precária para o tamanho da oferta e da demanda, que são fatores que podem ter influenciado a queda da oferta $e$ consequentemente ter feito com que o mercado tenha se retraído, frustrando a expectativa de crescimento, principalmente por já ter experimentado algumas temporadas de prosperidade, com taxas de crescimento exponencial.

Outro fator que limita o crescimento deste mercado no Brasil, segundo Wanessa Della Paschôa (2014), é o desestímulo decorrente das leis trabalhistas. Para a autora, o legislador brasileiro não permite a flexibilização que exige o atual mundo econômico e é exacerbadamente protecionista. Em sua visão, o ordenamento jurídico brasileiro fere o princípio da autonomia da vontade porque elabora leis trabalhistas que interferem nas disposições pactuadas entre o tripulante do cruzeiro marítimo e o armador-empregador e, por isso mesmo, são contraproducentes. Além disso, as empresas que exploram a atividade de cruzeiros marítimos no litoral brasileiro invocam ainda outros motivos para justificar a queda do mercado. Inclusive, algumas 
companhias marítimas vêm anunciando suas saídas do mercado de cruzeiros no Brasil.

É o caso da empresa Royal Caribbean International, conforme matéria divulgada na Forbes Brasil (BARBOSA, 2015), que anunciou, em nota à imprensa, divulgada em 8 de dezembro de 2015, que não passará pelo Brasil na temporada de 2016/2017. Questionada sobre a decisão, a companhia explicou que a mesma se deu em razão dos altos custos operacionais no país e do crescimento da atividade na Ásia e na Oceania, pois estas regiões têm feito inúmeros investimentos de infraestrutura e vêm apresentando cenários mais competitivos para a atuação no ramo.

Essas decisões, anunciadas pelas companhias marítimas que atuam no Brasil, no sentido de não mais explorar a atividade aqui, refletem a problemática do chamado "Custo-Brasil", o qual consiste num entrave que inibe a indústria desse ramo no país.

Os custos operacionais desencadeados pela atividade, como, por exemplo, taxas, impostos, incidência da legislação trabalhista e câmbio, são encarados como elementos que desfavorecem 0 crescimento e investimento das empresas proprietárias/armadoras de navios de cruzeiros no Brasil.

Entre os custos operacionais suportados pelas empresas armadoras, destaca-se aquele que é consequência de uma determinação dada pela Resolução Normativa (RN) n. 71/2006 do Conselho Nacional de Imigração (CNlg). Esta Resolução Normativa prevê a contratação obrigatória de marítimos brasileiros em embarcações estrangeiras quando do desempenho da atividade de turismo náutico no país.

É por meio dessa determinação legal que se protege o mercado de trabalho dos brasileiros em embarcações estrangeiras quando estas aqui operarem.

Para tanto, a RN n. 71/2006 do CNIg estabelece que a partir do 31ำ (trigésimo primeiro) dia de operação em águas jurisdicionais brasileiras, é obrigatória a contratação de, no mínimo, 25\% de brasileiros para o desempenho das atividades laborais a bordo. 
Neste sentido é a disposição contida em seu art. 7:

Art. $7^{0}$ - Transcorridos cento e oitenta dias da vigência desta Resolução Normativa, a partir do $31^{\circ}$ (trigésimo primeiro) dia de operação em águas jurisdicionais brasileiras, a embarcação de turismo estrangeira deverá contar com um mínimo de $25 \%$ (vinte e cinco por cento) de brasileiros em vários níveis técnicos e em diversas atividades a serem definidas pelo armador ou pela empresa representante do mesmo.

$\mathrm{Na}$ abordagem de Francisco Edivar Carvalho (2010) acerca do tema, o Conselho Nacional de Imigração (CNlg), ao editar a RN n. 71/2006, pretendeu restringir o trabalho de estrangeiros nesse ramo de atividade, bem como no trabalho de exploração de petróleo e na pesca oceânica, objetivando proteger o mercado de trabalho de brasileiros nas embarcações estrangeiras que operam em águas jurisdicionais brasileiras.

Segundo a Norma de Autoridade Marítima (NORMAM) 04/DPC, compreendem-se por águas jurisdicionais brasileiras (AJB):

[...] as águas interiores e os espaços marítimos, nos quais o Brasil exerce jurisdição, em algum grau, sobre atividades, pessoas, instalações, embarcações e recursos naturais vivos e não vivos, encontrados na massa líquida, no leito ou no subsolo marinho, para os fins de controle e fiscalização, dentro dos limites da legislação internacional e nacional. Esses espaços marítimos compreendem a faixa de duzentas milhas marítimas contadas a partir das linhas de base, acrescida das águas sobrejacentes à extensão da Plataforma Continental além das duzentas milhas marítimas, onde ela ocorrer (MARINHA DO BRASIL, 2013, p. 8).

A mesma resolução, em seu art. $8^{\circ}$, regula ainda a temporada de cruzeiros marítimos no Brasil e determina que os contratos de trabalho de tripulantes marítimos brasileiros sejam regidos pela legislação brasileira: 
Art. $8^{\circ}$ - Os brasileiros recrutados no Brasil e embarcados para laborar apenas durante a temporada de cruzeiros marítimos pela costa brasileira deverão ser contratados pela empresa estabelecida no Brasil ou na ausência desta, pelo agente marítimo responsável pela operação da embarcação, cujo contrato de trabalho será vinculado à legislação trabalhista brasileira aplicável à espécie (MARINHA DO BRASIL, 2013, p. 8, grifo nosso).

Parágrafo Único. Considera-se temporada de cruzeiros marítimos pela costa brasileira o período compreendido entre 30 (trinta) dias antes da partida da embarcação para o primeiro porto brasileiro até 30 (trinta) dias depois da saída do último porto brasileiro, incluindo neste período eventuais ausências das águas jurisdicionais brasileiras (MARINHA DO BRASIL, 2013, p. 8).

No ano de 2010, o Ministério Público do Trabalho e Emprego (MTE) e o Ministério Público do Trabalho (MPT) firmaram o Termo de Ajuste de Conduta (TAC) $\mathrm{n}$. 408/2010, o qual passou a viger em 26 de agosto de 2011.

O conteúdo do TAC reforça o objetivo da RN n. 71/2006 (CNlg), qual seja o de proteger o mercado de trabalho dos brasileiros em embarcações estrangeiras quando, por mais de 30 dias, navegarem pela costa brasileira. Mas, além disso, prevê que alguns dos direitos garantidos na Consolidação das Leis Trabalhistas se estendam aos brasileiros que forem submetidos a contrato internacional de trabalho (MINISTÉRIO PÚBLICO DA UNIÃO, 2010).

O TAC 408/2010 também garantiu aos tripulantes o direito de enviar, por transferência bancária, o salário percebido a título de remuneração, proibiu a cobrança dos materiais e uniformes de trabalho e exames médicos admissionais e obrigou que sejam disponibilizadas cópias do TAC, em língua portuguesa, para os trabalhadores a bordo (MINISTÉRIO PÚBLICO DA UNIÃO, 2010). 
Em princípio, é a Consolidação das Leis Trabalhistas quem rege, ou ao menos deveria reger, as relações de emprego dos marítimos brasileiros contratados para laborar a bordo de navios de cruzeiro durante a temporada brasileira.

No entanto, em fiscalizações realizadas por membros do Ministério Público do Trabalho em navios estrangeiros de cruzeiros marítimos verificou-se que, normalmente, as armadoras firmam contratos internacionais de trabalho com tripulantes brasileiros contratados para laborar na temporada brasileira em águas jurisdicionais brasileiras com o intuito de afastar a proteção da CLT e fazer incidir ao caso a Lei do Pavilhão (BRASIL, 2013).

Interessante notar a observação do Auditor-Fiscal do Trabalho, Sr. Raul Vital Brasil (2013, p. 1), quando da sua participação na Audiência Pública da Comissão de Direitos Humanos e Legislação Participativa do Senado Federal, realizada em outubro de 2013:

[...] uma das principais queixas apresentadas pelos brasileiros é que algumas empresas de navegação, para legitimar a utilização de contratos internacionais para os trabalhadores brasileiros, registram no contrato que o trabalhador permanecerá laborando depois que a embarcação deixar a costa brasileira, mas na prática acabam simplesmente dispensando esses trabalhadores no último porto brasileiro da temporada, ou passam a assediá-los para que peçam demissão, ou a aplicar advertências e outras punições disciplinares de forma desregrada, visando constituir histórico para justificar a dispensa por justa causa.

Objetivando reduzir custos, os armadores de navios de cruzeiros marítimos, além de fraudarem contratos de trabalho, dando a eles um viés internacional, adotam bandeiras de conveniência. Essas bandeiras são uma espécie de registro aberto pelo qual o proprietário da embarcação reduz consideravelmente os custos operacionais de sua atividade. 
No âmbito trabalhista, o maior impacto da adoção desse tipo de registro está concentrado na incidência da Lei da Bandeira nas relações de trabalho dos tripulantes. Dessa forma, os armadores elegem países com uma legislação trabalhista bastante frágil, causando a precarização do trabalho de tripulantes brasileiros a bordo de navios estrangeiros que desenvolvem a atividade de turismo náutico na costa brasileira.

\subsection{BANDEIRAS DE CONVENIÊNCIA: UMA ANÁLISE DE SEUS IMPACTOS NO ÂMBITO DAS RELAÇÕES DE TRABALHO DOS TRIPULANTES BRASILEIROS A BORDO DE NAVIOS DE CRUZEIRO MARÍTIMO}

O fenômeno da globalização, além das diversas características econômicas, sociais, culturais, advindas desta nova ordem mundial, demonstra a hegemonia no mundo contemporâneo da doutrina capitalista, em que busca por divisas e acumulação de capital de forma voraz. Na economia da navegação, a busca por competitividade e lucratividade fomentou a prática das chamadas Bandeiras de Conveniência (PLATCHEK, 2007).

A bandeira de conveniência, também denominada bandeira de favor, de aluguel ou de complacência, é uma estratégia econômica que compreende o registro do navio em países que não possuem regulação para o trabalho marítimo ou, quando possuem, é de má qualidade regulatória. Atualmente, essa estratégia empresarial é considerada como uma evasão legal, haja vista que o país de registro da embarcação não tem controle sobre o armador e sequer existe um vínculo genuíno entre o Estado de registro e o proprietário do navio (FONSECA NETO, 2010).

Sua utilização tem origem nos Estados Unidos, ainda no período da 20 Guerra Mundial. E, de acordo com Sardinha (2013, p. 23):

a ideia inicial seria autorizar que navios de proprietários dos EUA mudassem para a bandeira panamiana e como tal fossem utilizados para entrega de materiais no Reino Unido, sem que a sua utilização (ou a sua perda) arrastasse os EUA, contra sua vontade, para o conflito. Após a 
guerra, os benefícios puramente econômicos do sistema panamiano tinham-se tornado evidentes: iriam permitir à indústria do transporte marítimo evitar os altos custos com a contratação de tripulações americanas, permitir a redução do fardo que representavam os regulamentos mais exigentes, limitar as consequências financeiras de um eventual afundamento ou perda do navio.

Para compreender a internacionalização das relações de trabalho marítimo, ocasionada sobretudo pela proliferação de bandeira de complacência, é necessário que se entenda como funciona o processo de registro de uma embarcação. Segundo Martins (2013, p. 155), "o registro é um ato administrativo que confere nacionalidade às embarcações e o direito de ostentar a bandeira do Estado de Registro".

Assim, se um navio for registrado na Itália, diz-se que o navio é italiano, pois adquiriu, por meio do registro, a nacionalidade daquele país e, por isso, tem o direito de ostentar a bandeira italiana.

Existem duas espécies de registro de embarcações: o registro nacional e o registro aberto. A primeira se caracteriza pela exigência de vínculo prévio entre o país de registro e o navio, enquanto a segunda é marcada pela ausência da imposição de vínculo entre o Estado de registro e a embarcação e por normas mais flexíveis. $\mathrm{O}$ registro aberto divide-se em duas outras formas: bandeira de conveniência e segundo registro (MARTINS, 2013).

Para os fins da pesquisa acadêmica, se passará a análise individual do registro aberto denominado Bandeira de Conveniência, especialmente no que se refere aos impactos de sua proliferação no âmbito das relações de trabalho de tripulantes brasileiros empregados em navios de cruzeiro marítimo.

A Convenção das Nações Unidas sobre o Direito do Mar (CNUDM), ou simplesmente "Lei do Mar", representou um marco no desenvolvimento da regulação desta porção da Terra. Além de estabelecer um regime jurídico claro a ser cumprido, tanto no mar, como no seu espaço aéreo sobrejacente, no solo e no subsolo marinhos, também 
representa mais um passo na evolução do Direito do Mar que, na sua trajetória, oscilou entre as doutrinas que defendiam o mar como propriedade, e entre as que defendiam a liberdade total. A Convenção é o resultado da $3^{\text {a }}$ Conferência das Nações Unidas para o Direito do Mar (1973-1982), que chegou ao fim com a assinatura, em 1982, do tratado em Montego Bay (Jamaica) por 117 Estados. Foi aprovada no Brasil pelo Decreto Legislativo $\mathrm{n}^{\circ}$. 05, de 09 de setembro de 1987 e promulgada pelo Decreto $\mathrm{n}^{\circ}$. 1.530, de 22 de junho de 1985. Sua entrada em vigor ocorreu em 16 de novembro de 1994, um ano após a $60^{\mathrm{a}}$ ratificação, conforme previsto nos seus dispositivos. Após quase 14 anos em vigor, foi assinada por 157 e ratificada por 156 Estados (ONU, 2008). No desenvolvimento do texto final da Convenção, em função da importância do assunto e da premência de que a sua regulamentação fosse amplamente respeitada, adotou-se o critério do consenso, de forma que todos os dispositivos foram amplamente discutidos e a discussão só se esgotava quando o consenso era conseguido.

No dizer de Mello (2004, p. 1180): "esta Convenção vai além de uma simples codificação, uma vez que ela versa sobre muitos assuntos novos ainda não regulamentados elo costume". Dessa forma ela se reveste de grande importância, já que vai sedimentar diversos conceitos, alguns herdados do costume, outros já previstos em outros diplomas.

Sob esse aspecto, inicialmente cumpre destacar a disposição contida no artigo 91 da Convenção das Nações Unidas sobre o Direito do Mar (CNUDM), concluída em Montego Bay, no ano de 1982:

1. Todo estado deve estabelecer os requisitos necessários para a atribuição da sua nacionalidade a navios, para o registro de navios no seu território e para o direito de arvorar a sua bandeira. Os navios possuem a nacionalidade do Estado cuja bandeiras estejam autorizados a arvorar. Deve existir um vínculo substancial entre o Estado e o navio (Grifo nosso). 
Conforme se pode observar da literalidade do artigo supracitado, é indiscutível a exigência que se faz no sentido de haver uma relação substancial entre o Estado de registro e o navio.

Entretanto, se permite que o país de registro estabeleça critérios definidores para o aceite do registro. Com isso, ao mesmo tempo em que se exige a existência do vínculo substancial entre o navio e o Estado, a norma flexibiliza este importante princípio ao atribuir ao Estado da Bandeira o disciplinamento deste vínculo (MEIRINHO, 2014b).

Dessa forma, abre-se margem para que os Estados de registro optem por critérios extremamente frágeis para definição do que seria um vínculo substancial entre o Estado e o navio. Para Platchek (2007), a possibilidade de escolha do país em que se vai efetuar o registro da embarcação favorece a proliferação de bandeiras de aluguel, uma vez que, sendo livres para tomar essa decisão, os proprietários das embarcações optam por países que oferecem as melhores condições. Não por acaso, verifica-se que há um grande número de navios registrados em nações sem tradição no ramo, mas que possuem grandes frotas devido às vantagens ofertadas.

Os países que fornecem essa espécie de registro possuem pouca expressão econômica e, geralmente, cobram taxas mais baixas para as companhias de navegação, facilitando a obtenção do registro. Aos armadores que exploram suas frotas sob essas bandeiras são asseguradas vantagens (DABUL, 2008).

Sobre os efeitos que a adoção do registro aberto de bandeira de complacência produz, Marcelino André Stein (2011, p. 24-25) destaca que:

Os países que oferecem tal registro provocam distorções das mais variadas, como:

a) Dumping social, ao infringir as mais básicas legislações trabalhistas, submetendo muitas vezes as tripulações a condições indignas de trabalho; 
b) O frágil controle de normas ambientais concernentes a operações em alto mar, bem como, quando estas embarcações atracam nos portos do mundo inteiro e;

c) O frágil controle de normas de segurança marítima. Deve-se mencionar que os países que sediam registros de bandeiras de conveniência não possuem, via de regra, com relação aos navios registrados sob sua bandeira, nenhuma relação, além do fato de estarem estes navios registrados em seu país, que, por vezes, nem mar possuem, como é o caso da Bolívia e Mongólia.

O maior problema com relação às condições de trabalho a bordo de navios, segundo estudo realizado pela Organização Internacional do Trabalho (OIT), reside nas chamadas bandeiras de conveniência. Esses navios apátridas desrespeitam os preceitos da Organização das Nações Unidas (ONU), a qual estabeleceu a "Convenção ONU sobre Direito Marítimo" em 1982. Por esta ficou estabelecido que os Estados devem "exercitar eficazmente sua jurisdição e controle dos assuntos administrativos, técnicos e sociais sobre os navios de suas respectivas bandeiras" (MENDES, 2007, p. 15).

São as Leis do Estado da bandeira que incidirão sobre as relações jurídicas desenvolvidas a bordo. Por isso, os armadores utilizam a bandeira de favor como estratégia para reduzir custos. É dessa forma que os armadores garantem o lucro com a atividade empresarial (RAYMUNDO; ROMAY, 2014).

Apesar de ser um essencial fomento à livre concorrência - na visão dos armadores, o registro aberto de bandeira de conveniência faz com que se retroceda a estágios humilhantes de trabalho, de modo que o princípio basilar da Constituição Federal, o da Dignidade da Pessoa Humana, seja violado.

Com o objetivo de amparar a classe de trabalhadores marítimos, merece destaque 0 papel desenvolvido pela Federação Internacional dos Trabalhadores em Transportes 
(ITF), órgão responsável por tentar estender melhores normas e condições de trabalho para o maior número possível de marítimos (ITF, 2016).

Para isso, a ITF (2016), politicamente, busca firmar um acordo governamental que elimine o sistema de bandeiras de conveniência, exigindo que haja um vínculo genuíno entre a bandeira do navio e a nacionalidade ou residência de seus proprietários, gerentes e marítimos. Setorialmente, a federação tenta proteger os marítimos de situações de exploração, independentemente de suas nacionalidades.

\section{CONSIDERAÇÕES FINAIS}

O contrato de trabalho do marítimo apresenta elementos de estraneidade, na medida em que os sujeitos, o tripulante e o armador, possuem, frequentemente, nacionalidades diversas e, ainda, o navio costuma ser registrado em países sem vínculo genuíno com o empregador, conduta que se trata de uma estratégia empresarial, denominada no Direito Marítimo de bandeira de conveniência. Em razão disso, é dito que tal contrato possui conexão internacional, o que enseja um conflito espacial de normas trabalhistas.

Esse conflito de normas trabalhistas no espaço é solucionado, em regra, pela aplicação da Lei da Bandeira, orientação prevista no Código de Bustamante de 1928, que foi ratificado pelo Brasil, tendo aqui entrado em vigor em 1929. Esse o elemento de conexão empregado para reger as relações trabalhistas a bordo de uma embarcação.

Tendo em vista que, geralmente, o trabalho a bordo do navio se desenvolve em vários locais, a aplicação da Lei do Pavilhão, em tese, consiste numa facilitação do acesso à justiça pelo trabalhador, pois seria inviável que o trabalhador marítimo propusesse uma demanda trabalhista em cada local em que tenha prestado serviços. Entretanto, quando essa regra causar mais prejuízos do que benefícios ao tripulante marítimo, deve-se abrir espaço para a aplicação de elementos de conexão mais aptos a garantirem um patamar mínimo de direitos a ele. 
A prática de adoção de bandeiras de conveniência fere o princípio da ordem pública porque constitui fraude à lei. Não fosse o bastante, essa prática resulta na precarização do trabalho marítimo, especialmente quando desenvolvido a bordo de navio destinado ao turismo náutico, onde as jornadas, por vezes, acabam superando 14 horas diárias, tendo em vista que, por ser uma espécie de hotel flutuante, há a necessidade de se manter tudo em ordem para o melhor atendimento dos passageiros, o que faz com que os trabalhadores embarcados sejam submetidos a condições degradantes de trabalho com jornadas exaustivas.

Como forma de combater essa prática, o Poder Judiciário brasileiro tem admitido o afastamento do elemento de conexão da Lei do Pavilhão, regra geral aplicável ao trabalho desenvolvido em navio, para aplicar ao caso concreto o Princípio do Centro de Gravidade, o qual leva em consideração o centro de gravidade da relação jurídica.

Pela Lei do Pavilhão, são aplicadas às relações jurídicas a bordo as leis do território em que o navio foi registrado. Enquanto pelo Princípio do Centro de Gravidade, se dá ao juiz a possibilidade de verificar onde a relação jurídica produziu mais efeitos. Assim, seja pelo fato de ter aqui laborado, ainda que parcialmente, seja pela pré-contratação ter ocorrido em solo nacional, se ficar constatado que a demanda trabalhista do tripulante tem uma maior ligação com o ordenamento jurídico brasileiro, é este quem deve reger seu contrato de trabalho, atraindo, portanto, a aplicação da Consolidação das Leis do Trabalho.

Além disso, relembre-se que no topo da pirâmide de hierarquia das normas trabalhistas encontra-se o Princípio da Norma mais Favorável, pelo qual até mesmo a legislação trabalhista nacional poderá ser afastada, caso fique evidenciado que seja ela mais desfavorável do que a lei estrangeira.

É certo que a Convenção sobre o Trabalho Marítimo de 2006 se constitui num conjunto de garantias mínimas aos trabalhadores marítimos. Contudo, no que a legislação pátria for mais favorável, deve ser afastada, inclusive, a Convenção. 
Desse modo, tanto na hipótese em que o tripulante brasileiro é contratado em solo nacional para laborar em águas jurisdicionais brasileiras quanto na hipótese em que é contratado para laborar parcialmente aqui, se verificado que o centro de gravidade da relação de trabalho encontra-se no Brasil e que é esse o direito que lhe é mais benéfico, não há razão para se aplicar a Lei do Pavilhão quando utilizada a bandeira de conveniência para se esquivar da aplicação da lei brasileira.

Isto posto, ressalta-se que a presente pesquisa acadêmica, longe de esgotar o assunto, se propõe a uma reflexão acerca desta forma globalizada de precarização do trabalho, com o intuito de se flexibilizar a regra geral da Lei da Bandeira, visto que sua aplicação, de forma engessada, tende a comprometer o objetivo do Direito do Trabalho, que é o de tutelar o sujeito hipossuficiente da relação de trabalho.

O Poder Judiciário brasileiro tem o papel de descontruir regras até então consideradas absolutas, fazendo valer, em casa caso concreto, aquilo que for mais justo. Frise-se, a Lei do Pavilhão não é critério absoluto para resolução de conflito espacial de normas trabalhistas. Por isso, deve perder espaço quando constatada a hipótese da bandeira de conveniência como manobra para elidir a aplicação da legislação nacional, de forma a se desprestigiar a concorrência desleal entre as companhias marítimas, preferindo-se, sempre, elevar e consagrar a dignidade da pessoa humana e o valor social do trabalho. Jamais deve ser permitido que empregadores obtenham lucros em detrimento do trabalho humano.

\section{REFERÊNCIAS}

AMARAL, Ricardo Costa Neves do. Uma análise do mercado de cruzeiros marítimos evolução, expansão e previsão no Brasil e no mundo. 2009. $180 f$. Doutorado em Ciências da Comunicação) - Departamento de Relações Públicas, Propaganda e Turismo da Escola de Comunicações e Artes da Universidade de São Paulo, 2009.

AMORIM, Edgar Carlos de; OLIVEIRA JÚNIOR, Vicente de Paulo Augusto de. Direito internacional privado. 13. ed. Leme: Mizuno, 2014. 
BARBOSA, Isabela. Royal Caribbean não passará pelo Brasil na temporada 2016/2017. Brasil Forbes, 8 set. 2015. Disponível em: <http://www.forbes.com.br/negocios/2015/12/royal-caribbean-nao-passara-pelobrasil-na-temporada-20162017/>. Acesso Jan de 2020.

BARROS, Alice Monteiro de. Contratos e regulamentações especiais de trabalho: peculiaridades, aspectos controvertidos e tendências. 4. ed. São Paulo: LTr, 2010.

. Curso de direito do trabalho. 10. ed. São Paulo: LTr, 2016.

BELFORT, Fernando. O direito internacional do trabalho e a aplicação da norma mais favorável nos contratos internacionais de trabalho com o cancelamento da Súmula $\mathrm{n}$. 207 do TST. Revista Fórum Trabalhista. Belo Horizonte, v. 3, n. 14, p. 69-93, set./out. 2014.

BOMFIM, Bianca Neves; CARELLI, Bianca Neves. A jornada de trabalho em navios de cruzeiro. Justiça do trabalho. Porto Alegre, v. 32, n. 378, p. 73-81, jun. 2015.

O trabalho realizado em navios e a aplicação da legislação material trabalhista. Revista LTr: Legislação do Trabalho. São Paulo, v. 80, n. 06, p. 680684, jun. 2016.

DABUL, Renata Engler Velloso. Bandeiras de Conveniência: benefícios e malefícios. 2008. Trabalho de Conclusão de Curso em Ciências Náuticas do Curso de Formação de Oficiais de Náutica (FONT) da Marinha Mercante) - Centro de Instrução Almirante Graça Aranha. Rio de Janeiro, 2008.

DELGADO, Mauricio Godinho. Curso de direito do trabalho. 15. ed., rev. e ampl. São Paulo: LTr, 2016.

DOLINGER, Jacob. Direito Internacional Privado: contratos e obrigações no direito internacional privado. Rio de Janeiro: Renovar, 2007.

FGV PROJETOS. Cruzeiros Marítimos: estudo de perfil e impactos econômicos no Brasil. Temporada 2014-2015. 2015. 
MARTINS, Eliane Maria Octaviano. Curso de direito marítimo: teoria geral. 4. ed. atual. e ampl. Barueri: Manole, 2013.

OIT - CONVENÇÕES DA ORGANIZAÇÃO INTERNACIONAL DO TRABALHO. Decreto-Lei n. 480, de 8 de junho de 1938. Aprova a Convenção relativa à admissão de menores ao trabalho marítimo, firmada em Genebra a 5 de dezembro de 1936, por ocasião da 22aㅡ sessão de Conferência Internacional do Trabalho. (Convenção n. 058).

PASCHÔA, Wanessa Della. Trabalho em cruzeiros marítimos: legislação brasileira versus normas internacionais. Jornal Trabalhista Consulex, Brasília, v. 31, n. 1.527, p. 3-8, maio 2014.

PEREIRA, Simone Rocha; ROBLES, Léo Tadeu. Cruzeiros Marítimos: o turismo de viagem e o Porto de Santos. In: SEMEAD: SEMINÁRIOS EM ADMINISTRAÇÃO, 30. Anais... set. 2010.

PLÁ RODRIGUEZ. Américo. Princípios de direito do trabalho. 3. ed. atual. São Paulo: LTr, 2002.

PLATCHEK, Ricardo Moisés de Almeida. As Bandeiras de Conveniência e a Segurança Mundial. In: CASTRO JÚNIOR, Osvaldo Agripino de (Org.). Direito marítimo made in Brasil. São Paulo: Lex, p. 457-491, 2007.

RAMÔA, Carlos Eduardo de Almeida; FLORES, Luiz Carlos da Silva. Cruzeiros marítimos: realidade da oferta e da demanda no mercado brasileiro. Revista de Turismo Contemporâneo - RTC, Natal, v. 2, n. 2, p. 300-322, jul./dez. 2014.

Enviado: Fevereiro, 2020.

Aprovado: Março, 2020. 